\title{
Using Debate In Helping Students Discuss Controversial Topics
}

Carolyn R. Fallahi, (E-mail: Fallahic@ccsu.edu), Central Connecticut State University Joseph D. Haney, Central Connecticut State University

\begin{abstract}
We used 2 debates over the course of a semester to encourage upper level psychology students to engage in discussion about controversial issues. The debates considered issues in Affirmative Action and sexual diversity. Students completed a survey assessing their experiences both individually and as a team member. Students found it easier to discuss controversial subjects in the classroom during a structured debate as compared to traditional open discussions. In addition, most of the students enjoyed the debate, would like to participate in a debate in the future, and felt empowered by the experience. The debate itself elicited some strong emotions, both positive and negative. Debate is a useful tool to facilitate verbal participation by students in classes where the subject matter is controversial.
\end{abstract}

\section{INTRODUCTION}

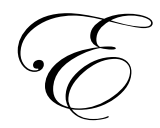

ngaging students in classroom discussions of controversial topics can be a formidable task for instructors of undergraduate psychology courses. Encouraging meaningful discussions may be even more daunting. Some instructors avoid discussions of controversial issues in their classrooms altogether for fear of alienating students and discouraging shy or less verbal students. Others wish to avoid poorly formulated responses or awkward lapses of discussion in the classroom (Johnson \& Johnson, 1988; Lusk \& Weinberg, 1994).

Despite these drawbacks, students often view classroom discussion as valuable and believe that participation enhances the learning experience. However, not all students add their voice to classroom discussions because of possible criticism from their peers, fear of receiving a poor grade, perceived lack of knowledge about the topic under discussion, or insufficient time to think about their response (Hess, 2001; Lusk \& Weinberg, 1994). Hyde and Ruth (2002) evaluated reasons why master's of social work students self-censored and did not participate in discussions of controversial topics. The most common reasons for self-censorship cited by first-year students were shyness, lack of preparedness, personal nature of the topic, large class sizes, and fear that they would be viewed as stupid by the instructor or their classmates.

The ability to engage in a constructive discussion of controversial topics fosters an appreciation of opposing viewpoints and is a key element of good citizenship (Johnson, Johnson, \& Smith, 1997; Oulton, Day, Dillon, \& Grace, 2004). Khan (1999) found that some students who participated in interactive, instructor-driven discussions in an undergraduate course on the psychology of racism rethought their prejudices following exposure to open discussions of this controversial and sensitive topic. Classroom debate is a related teaching technique that may provide a significant learning experience for students and increase classroom participation. To engage in a debate is to discuss opposing views through social interaction. Preparing for a debate requires students to use library resources, take notes, define terms, formulate arguments and rebuttals, develop critical thinking skills, and work as a team. Debating a controversial subject improves listening and public speaking skills, enhances appreciation for the complexities of a controversial subject, and challenges prior beliefs (Bell, 1982). In other words, debate is an excellent form of active learning. Further, students are more likely to retain learned content when they apply basic psychology concepts to real-world issues (Bell, 1982; Garland, 1991). 
The structure of classroom debate takes on many different forms. Lewin and Wakefield (1983) employed debate between two psychology instructors and concluded that this didactic technique increased student interest in the topic and spurred independent scholarly research compared to a traditional lecture-driven courses. Garland (1991) found that the use of point-counterpoint panel discussions of controversial subjects in undergraduate psychology courses was useful in teaching course content, honing critical thinking skills, and increasing classroom participation. Green and Klug (1990) evaluated the use of debate in a large undergraduate sociology course and observed that classroom discussion increased even among students who were not actively involved in the debate itself. Moeller (1985) used debate in an undergraduate developmental psychology course to teach about controversial topics and improve students' critical thinking and verbal communication skills. Students evaluated the debates using a 10-item Likert scale in which higher scores indicated a more valuable learning experience. Mean scores of 7.34 (SD 2.07) and 7.28 (SD 1.82) indicated that students found that participating in the debate process and observing it, respectively, were both valuable learning experiences. Elliot (1993) used a similar structured debate format in an undergraduate course on the psychology of women to encourage classroom participation and facilitate critical thinking. The evaluation included generic student comments taken from the college-wide course evaluation form. The author concluded from the students' comments on the evaluation forms that, by its very nature, debate increased classroom participation.

Finken (2003) examined 151 undergraduate students enrolled in a human sexuality course. She found that debates had a moderating impact on students' attitudes. Following the debate, students reported less extreme attitudes following the debate. Further, Budesheim \& Lundquist (1999) found that students who argued against their current belief on an issue produced a biased assimilation, but students who argued for a belief that was in line with their attitudes did not produce this effect.

Central Connecticut State University, like many other universities, includes a mandatory multicultural component in its psychology curriculum. The Psychology Department requires undergraduates to take one of two courses, either Psychology of Diversity or Cross-Cultural Psychology. Both are upper level psychology courses typically taken by juniors and seniors. The Psychology of Diversity instructor found that students had difficulty discussing controversial issues. Students feared that they would "say the wrong thing" or that their beliefs might not be "politically correct." In response to this issue, the instructor (C.R.F.) instituted two formal debates over the course of one semester. We hypothesized that the use of debate would provide an atmosphere where undergraduate psychology students could become more open-minded about controversial topics, more openly participate in classroom discussions, and minimize self-censorship.

\section{METHOD}

\section{Participants}

Fifty-five students from two Psychology of Diversity classes engaged in two debates and completed a 25item survey immediately following the second debate. Most of the students were juniors and seniors $(N=50 ; 91 \%)$. While survey completion was voluntary, students turned in a debate packet that included the survey and were reminded throughout the semester to turn it in. They did not receive any incentives for their completion of the survey.

\section{Procedure}

Affirmative action was the topic of the first debate. Students considered the following statement: "Affirmative Action is a necessary remedy for minorities because of a long history of traumatic events including racism, poverty, and a history of individual and social problems." The statement for the second debate focused on sexual diversity: 'We are living in a time where sexual diversity should be embraced. Gays and Lesbians should be allowed to marry and raise children within a supportive community'. 
The instructor randomly divided students into two teams for each debate. One team took the affirmative side and the other the negative side. Students could choose from a variety of roles on their team, including speaker/debater, rebuttal speaker, researcher, organizer, moderator, leader, and speech composer. Many students volunteered for more than one role. Students prepared for each debate by researching the topic, communicating and collecting information from team members, composing speeches and rebuttals, and participating during the debate. In addition to participating in the debate process, all students completed a fully referenced, written summary of the team's research.

Students used three to four class periods to prepare for the debate. A student moderator managed each of the debates. On debate day, team members presented an introduction, four to five main points in support of their argument, and a conclusion all lasting no more than $10 \mathrm{~min}$. This involved four to five students in support of their argument; one student providing the introduction, and one student providing the conclusion. On each side there were four "official" students who provided the first round of rebuttals. After they finished their arguments, the rebuttal session was opened up to all students. The instructor took notes during the debate to ensure that every student participated. The moderator did not allow interruptions from the opposing side during the speeches. Rebuttals lasting 8 to $10 \mathrm{~min}$ followed each presentation. The moderator allowed each team equal time to present their arguments and state their rebuttals.

During the second debate, team members who did not compose speeches and rebuttals during the first debate where mandated to participate in those jobs. This made sure that no student could hide in a role which did not require public discussion of an uncomfortable idea.

The students themselves decided the outcome of each debate. After the debate was over, students voted for the winning side. Anecdotally, students did not always vote for their own team. Rather, they voted for the team that presented the most persuasive arguments.

\section{Attitude Measure}

We asked students if they agreed with the debate statement before each debate and immediately following its conclusion. We used a 5-point Likert scale to measure the extent of agreement, $1=$ strongly disagree; and $5=$ strongly agree.

\section{Grading}

Students received two grades for each debate. The first was an individual grade based on the instructor's evaluation of their performance during the debate and their written summary of the team's research. The second grade was a team grade based on ratings provided by every member of the team. The instructor summarized ratings and individual comments for each student. Each debate was worth 100 points or $1 / 5$ th of the overall grade for the semester.

\section{Survey Instrument}

The survey consisted of a combination of Likert scale items and open-ended questions. The areas covered by the survey included the students': (1) Understanding of the debate process, (2) Assessment of the topic's controversy rating, (3) Assessment of the ease of discussing controversial topics in a debate situation, (4) Experiences during the debate, (5) Role (s) in the debate; time spent preparing for the debate; and an evaluation of the process, \& (6) Assessment of the teamwork aspect of debate. 


\section{RESULTS}

Most of the students had no prior experience with debate. Nonetheless, most believed that they understood the debate process (89\%), enjoyed the debate (77\%), and enjoyed their roles on the debate team (75\%). Students believed that they spent a substantial amount of time preparing for the debate (92\%), and indicated that they put forth their best effort in preparing for the debate assignments (85\%). Most indicated that they would like to take part in another debate in the future (80\%). Most of the students viewed the two topics as controversial (89\%).

According to the survey findings, most students believed that the debate changed their personal standpoint on the topic $(80 \%)$. A measure of attitudes conducted before and after each debate provides an interesting story when analyzed with a paired $t$ test. Students endorsed Affirmative Action more positively following the debate $(M$ $=3.43, \mathrm{SD}=.920)$ as compared to before the debate $(M=2.06, \mathrm{SD}=1.00) ; t(53)=-8.166, p<.001$, two tailed. In contrast, students tended to agree with the sexual diversity statement prior to the debate $(M=4.09$,

$\mathrm{SD}=.59) ; t(53)=-1.352, p=.182$, two tailed, and their attitude did not change significantly as a result of the debate $(M=4.15, \mathrm{SD}=.60)$.

Most of the students endorsed the view that debating a controversial topic was easier than discussing controversial topics openly in class (82\%). In fact, many believed that they would be more likely to experience anger, frustration, worry, sadness, and nervousness if they were to share their personal feeling in the classroom during group discussions or lectures, rather than debate an assigned standpoint (74\%). Nearly two-thirds of the students believed that they would not be likely to share their personal feelings in class for fear that they might not be politically correct $(64 \%)$.

The debate elicited some strong emotions. Some students felt angry (42\%) at some point during the debate. When asked to explain their feelings of anger, $36 \%$ of the students stated that people on the opposing side were disrespectful and made offensive comments. Others did not like being unable to speak out of turn until called upon by the moderator (13\%), whereas 7\% did not like presenting information that they did not believe. In addition, 9\% of the students were angry when speakers on the opposing team were ineffective or unprepared for the debate.

Half of the students felt frustrated at some point during the debate $(50 \%)$ because they were not able to present points that were in agreement with their beliefs $(24 \%)$, not allowed to speak unless called upon by the moderator $(22 \%)$, or they were worried that they would not communicate their arguments effectively (15\%). Other sources of frustration were team members who did not do their part (7\%) or were perceived as disrespectful during the debate (15\%), and the opposing team's strategies of stating some points more than once (9\%). Students also experienced worry $(45 \%)$ and anxiety $(55 \%)$ while preparing for the debate or during the debate. The most frequently cited reasons were worry about speaking during the debate $(33 \%)$, fear that team members would not be prepared (18\%), and worry about others' reactions $(20 \%)$.

We asked students about their experiences working on a team. A total of $80 \%$ experienced a feeling of group accomplishment or teamwork during the debate, and $64 \%$ preferred working with a team rather than working alone. Many believed that their team members were organized and worked well together (53\%) and were cooperative $(22 \%)$.

Finally, $48 \%$ of the students experienced a sense of empowerment during the debate. When asked to explain, 53\% indicated that the empowerment came from having a debate team that made great arguments, whereas $25 \%$ felt empowered because they made valid points and spoke effectively. Other students experienced empowerment because of encouragement from their teammates (25\%). 


\section{DISCUSSION}

Students in an upper level psychology of diversity class participated in two debates during the semester on Affirmative Action and on sexual diversity and family life. Students received both individual and team grades for their participation. The students enjoyed the debate and believed that it helped them discuss sensitive or controversial topics more easily. Half of the students who participated in the debate believed that being an effective speaker and working with their teammates led to a feeling of empowerment. Most enjoyed working in a team atmosphere. Negative emotions did arise during the debate, including performance anxiety, concern over lack of preparation, or worry about the arguments chosen by the opposing team. Participation in the debate actually led to a more positive change in attitudes for the Affirmative Action debate, but not the sexual diversity debate. These results are in line with Johnson and Johnson's (1985) study that examined controversial debates. They found that students were more likely to increase the amount of time they spent rehearsing, mastering, and searching for information for a controversial debate. In addition, they found that controversial debates lead to the most attitude change. Students in this study did experience significant attitude change for the Affirmative Action debate but not for the sexual diversity debate. One possible explanation is that prior to this course, students were not exposed to much information about Affirmative Action, but were very familiar with the arguments associated with the sexual diversity debate.

Educational pedagogies, like Shulman's (2004) taxonomy, incorporate (1) commitment to the learning process, (2) knowledge and understanding of the material, (3) working with the knowledge that the student has learned, (4) taking time to think about and evaluate that knowledge, (5) comparing alternatives, and (6) ultimately judging that information such that the student evaluates and understands how that information fits with their own emerging identity are necessary prerequisites to higher-order thinking. Controversial debates are a nice tool to challenge students to do more than passively learn both sides of an argument.

While many of the students believed that it was easier to discuss controversial topics within a debate structure, this information came from survey data. Therefore, it seems that the next step to this inquiry might be to provide empirical evidence that supports this claim by comparing a class in which the level of discussion was in fact compared with another class that did not participate in a debate. Further, we wonder whether or not the debate process encourages students to discuss controversial issues outside of the debate context and whether or not debate helps students who would normally not engage in a free discussion related to controversial topics.

On a personal note, many of the students were nervous about public speaking and the instructor (C.R.F) witnessed many students working together to help their team members overcome their fears of speaking in public. Anecdotally, prior to both debates, students were very excited. We heard from other instructors that their students were talking about the upcoming debate and that many faculty members and students knew that the debate was approaching. In conclusion, the use of debate was a valuable technique for increasing classroom discussion of controversial topics. The debate assignments created a great deal of anticipation and excitement among undergraduate psychology students.

\section{ACKNOWLEGEMENTS}

1. We thank Sara R. Fallahi for her help in coding most of the data for this study.

2. Editorial assistance was provided by Sally K. Laden, MS. 


\section{REFERENCES}

1. Bell, E. P. (1982). Debating controversial issues. History Teacher, 15, 207-223.

2. Budesheim, T. L., \& Lundquist, A. R. (1999). Consider the opposite: Opening minds through in-class debates on course-related controversies. Teaching of Psychology, 26(2), 106-110.

3. Elliot, L. B. ((1993). Using debates to teach the psychology of women. Teaching of Psychology, 20, 3538.

4. Finken, L. L. (2003). The complexity of student responses to in-class debates in a human sexuality course. Teaching of Psychology, 30(3), 263-265.

5. Garland, D. J. (1991). Using controversial issues to encourage active participation and critical thinking in the classroom. Community/Junior College Quarterly of Research and Practice, 15, 447 - 451.

6. Green, C. S., \& Klug, H. G. (1990). Teaching critical thinking and writing through debates: An experimental evaluation. Teaching Sociology, 18, 462 - 471.

7. Hess, D. (2001). Teaching students to discuss controversial public issues. ERIC Digest. ERIC Clearinghouse for Social Studies/Social Science Education: Bloomington, IN. (BBB24392).

8. Hyde, C. A., \& Ruth, B. J. (2002). Multicultural content and class participation: Do students self-censor? Journal of Social Work Education, 38, 241 - 256.

9. Johnson, D. W., \& Johnson, R. T. (1985). Classroom conflict: Controversy versus debate in Learning groups. American Education Research Journal, 22(2), 237-256.

10. Johnson, D. W., \& Johnson, R. T. (1988). Critical thinking through structured controversy. Educational Leadership, 45, $58-64$.

11. Johnson, D. W., Johnson, R. T., \& Smith, K. A. (1997). Academic controversy: Enriching college instruction through intellectual conflict. ASHE-ERIC Higher Education Report, 25(3), 1 - 157.

12. Khan, S. R. (1999). Teach an undergraduate course on the psychology of racism. Teaching of Psychology, 26, $28-33$.

13. Lewin, L. M. \& Wakefield, J. A. Jr (1983). Teaching psychology through an instructor-debate format. Teaching of Psychology, 10, $115-116$.

14. Lusk, A. B., \& Weinberg, A. S. (1994). Discussing controversial issues in the classroom: Creating a context for learning. Teaching Sociology, 22, $301-308$.

15. Moeller, T. G. (1985). Using classroom debates in teaching developmental psychology. Teaching of Psychology, 12, $207-209$.

16. Oulton, C., Day, V., Dillon, J., \& Grace, M. (2004). Controversial issues - Teacher's attitudes and practices in the context of citizenship education. Oxford Review of Education, 30, $489-507$.

17. Shulman, L. S. (2004). Teaching as community property: Essays on higher education. San Francisco: Jossey-Bass Publishers. 